\title{
GCU
}

Glasgow Caledonian

University

University for the Common Good

\section{In the absence of hard data, is soft data better than no data at all?}

\section{Dalgarno, Phil}

\section{Published in:}

Addiction Research and Theory

DOI:

10.1080/16066359.2017.1380191

Publication date:

2018

Document Version

Author accepted manuscript

Link to publication in ResearchOnline

Citation for published version (Harvard):

Dalgarno, P 2018, 'In the absence of hard data, is soft data better than no data at all?', Addiction Research and Theory, vol. 26, no. 2, pp. 159-162. https://doi.org/10.1080/16066359.2017.1380191

\section{General rights}

Copyright and moral rights for the publications made accessible in the public portal are retained by the authors and/or other copyright owners and it is a condition of accessing publications that users recognise and abide by the legal requirements associated with these rights.

Take down policy

If you believe that this document breaches copyright please view our takedown policy at https://edshare.gcu.ac.uk/id/eprint/5179 for details of how to contact us. 
In the absence of hard data, is soft data better than no data at all?

\section{Introduction}

Between 1996 and 1999, the author was Research Fellow on a project investigating a non-clinical and non-criminal heroin using population.

The inclusion criteria for this study were that participants had non-medically used opiates at least 10 times in each of the previous 2 years, had never received any specialist addiction treatment for any drug (including alcohol), and had never served a custodial sentence.

In total, 176 participants were interviewed for the project; the methodology stated that each of these would be required to be interviewed in total three times over the space of 36 months. For a number of different reasons, 126 participants were interviewed the required three times. What the results of this study indicated was that, under the correct conditions, it was hypothetically possible to use opiates in general and heroin specifically over a number of years without necessarily encountering the problems normally associated with the non-medically supervised use of these substances. The results of both the pilot study and the main study have been published (Shewan, Dalgarno, Marshall, Lowe et al 1998; Shewan and Dalgarno, 2005). These findings have been replicated to a degree by a similar study conducted in England (Warburton, Turnbull \& Hough 2005; McSweeney \& Turnbull, 2007).

In 2011 the author applied for further funding to revisit this cohort in order to follow them up with a view to investigating whether or not they still used heroin and, if so, 
whether their use could still be regarded as non-problematic, and if not, had any of them sought specialist treatment? It was assumed that a number of the group would have discontinued use, in which case the questions would focus on why had they decided to stop and how had they managed it: had they sought some form of medical assistance, had they "done it themselves" or had they simply stopped without thinking about it?

In the event, the application was rejected. There were several reasons given for this by the funding organisation, principal of which was the reliance in the proposed follow-up study on subjective "soft" data, in the form of self-complete questionnaires.

In 2013 , the author met with medical colleagues to discuss further possibilities for this cohort, this time addressing the specific issues that had been raised by the reviewers of the application two years earlier.

Rather than using self-complete questionnaires, it was proposed that "hard" data, in the form of medical records be accessed via a number of NHS databases, and the non-problematic heroin cohort compared with an age and gender matched "normal" population sample along with another sample of stable methadone users (also age and gender matched). The method was straightforward: health and medical data for the three groups would be tracked and compared for the years 1996/7, 1999 and 2012. This would give some indication of whether the study group were more or less healthy than the two comparison groups in terms of GP visits, hospitalisations, psychiatric problems and so forth. This was a clear and simple plan and would generate a considerable amount of data for analysis based upon objective medical records rather than subjective self-reporting and interviewer observation. 
In order to do all of this, however, the real names of the original participants along with their date of birth would be required. Ideally, postcodes for their addresses in 1996/7, 1999 and 2012 should also be provided. Lastly, a signed consent form would be required in order to gain access to their medical records.

The potential problems with this were immediately clear as information of this sort was precisely what had not been asked for at the time of the original project, where the only details collected were gender, age, occupation of the participant and the occupations of their parents. This was one of the basic assurances given to participants at the outset of the 1996 study and was regarded as an absolute necessity. Had this assurance not been given then it is doubtful that the project would have progressed beyond the pilot stage. The current emphasis on verifiable medical and other such "hard" data as a means of squeezing further value for money out of a project is not feasible in the case of individuals or groups who have not come to the attention of the medical/addiction or criminal justice systems.

These concerns notwithstanding, a number of discreet messages were posted on social networking sites, a number of telephone calls made and a number of meetings held. Within ten days there had been direct responses from over fifteen individuals (all male), two of these were on behalf of an undisclosed number of other parties. Another individual made contact on behalf of himself and two others, all three of whom are currently in specialist addiction treatment. None of the others who made contact had been or were currently in treatment.

The majority of replies came from individuals who had been key contacts on the 1996 project. In essence, they had been participants at an early stage and had agreed to approach others in their social group of heroin users with a view to 
recruiting them to the study. A number of these outreach people were used throughout the study, and the author maintained contact of sorts with some of them at the end of its lifespan. This provided a means of indirectly keeping in touch with those individuals they had introduced to the project. Using the original key contacts as a buffer between participants and researcher also provided a reasonable means of further protecting the participants' anonymity, as it would be left up to them whether they wanted to participate in a follow-up or not via a proxy.

With the exception of those in treatment, none of the others were prepared to take part in the proposed study despite taking the time to contact the author. There were several reasons given for this decision (none of which relate to health concerns, interestingly). These were as follows:

1. "Owning up to" an illegal activity, in this case, heroin use. None of those who made contact had attracted the attention of the police (this applied to the problem users now in treatment) and signing a consent form for a project investigating their heroin use was regarded as tantamount to signing a confession.

2. Related to the above (and arguably more important) was the issue of stigma (and public shame) to the participant should the data ever "get into the wrong hands" resulting in them being "outed" as heroin users (whether current or former). It was thought that should this knowledge become public then their livelihoods, reputations and relationships with others (in some cases, their spouses, who were unaware of this part of their lives) would be jeopardised. 
3. While every reassurance was given as regards ethics, particularly around anonymity and confidentiality, the correspondents remained resolutely unconvinced. There was concern expressed that the rules/laws covering ethics could be changed at some point in the future leading, again, to potential exposure as a heroin user, linking back to concerns 1 and 2 (above).

4. Concerns were raised about the security of the data, with a number of people raising the issue of high profile stories in the media about NHS laptops and data sticks being left in taxis, cafes and so forth.

In short, none of these non-criminal, healthy adults appeared to have any great faith or trust in what they perceive as governmental agencies - in this case the NHS and the university system - and by extension the government itself. It should be noted that this mistrust was present in those individuals in treatment as well, even though they were prepared to provide the required details, taking the view that, as they were already "in the system" everything was known about them already and that they had little to lose in this respect.

That said, all of those who took the step of, as it were, making the initial move and getting in touch were amenable to the idea of a one on one interview with no identifiers (other than those used in the original study: age, gender, occupation) being conducted in a place of their choice by a discreet and experienced interviewer.

\section{Discussion}

This situation clearly poses a problem in terms of research involving the intersection of health and illegal activity, particularly where the activity - in this case the use of a substance commonly regarded as highly addictive - has to date been conducted 
discreetly and unobtrusively enough so as not to result in any clear or obvious health problems, nor attracted the attentions of the law enforcement agencies.

On the face of it, the situation appears to be quite clear cut; black and white, so to speak. On one side we have those who abstain from the consumption of any sort of (illegal) intoxicant, and on the other we have a group of highly problematic and highly visible users who are already involved with addiction services and/or the criminal justice system due at least in part to the severity of their drug problem(s): in reductionist terms, one is either abstinent or one is an addict.

However, sitting between these two extremes, there is a third, very heavily populated "grey middle group". One would assume that anyone working in the drugs field will at the very least be aware of the people populating this group: they are not abstinent but nor are they especially problematic, and will use a particular illegal drug (usually, but not always, cannabis) or perhaps a range of illegal drugs (usually, but not always, stimulants and "party drugs" such as Ecstasy, amphetamines and LSD). A number of them will use drugs which, to the uninitiated or uninformed, are usually associated with the highly problematic group, drugs such as cocaine, crack cocaine and the opiates, specifically heroin.

Due to the fact that nothing current is really known about this group, what follows is largely educated guesswork on the part of the author; these are drug or ex-drug using non-criminals most of whom are now completely integrated into some social group with all the trappings and status symbols accompanying that. From the responses received to the "invitation to participate" messages, it would seem that many/most of their friends know nothing about their opiate/drug use (either current or past); this may be a wise strategy, as users of substances generally regarded 
(often erroneously) as "recreational" such as Ecstasy can often take a negative view of heroin use (e.g. McElrath \& McEvoy, 2001; Finnigan, 1996).

There is the added possibility that their partners do not even know about their heroin use. It has been proposed that popular views and beliefs regarding how drug users "are" can stigmatise and thus negatively affect users (and probably, in this case, former users). This applies particularly when the views and beliefs stem from ignorance and misinformation (Palamar, 2013, Palamar et al, 2013).

Brown (2015) makes the point that stigma may be more or less severe depending on the drug involved; his study comparing levels of stigma towards cannabis users with heroin users, indicate that the "harder" a substance is considered to be, the greater the levels of stigma are.

These findings are in accordance with a study conducted by Palamar (2012) regarding stigma perceptions towards those who use substances ranging from those considered "soft" to those considered "hard". The overall suggestion is that users of "hard" drugs may be more affected by stigma.

As an aside, it is noteworthy that all of the studies the author reviewed regarding substance use and the resulting stigma (perceived or otherwise) focus on current and/or problem use as opposed to previous and/or occasional use. Regardless, the perceived impacts of having been a heroin user in the past, occasional and controlled or otherwise, do appear to cast a long shadow.

It could be assumed from the above that the participants in the proposed study were (understandably) concerned about stigmatising arising from past behaviours that 
they either no longer indulge in, or indulge even more discreetly than previously: post hoc stigmatising, as it were.

With all the hullaballoo and stigma associated with drug use (e.g. Boekel et al 2015; Erofeeva, 2016; Scheibe, 2017) - let alone the use of a "demon drug" like heroin the reluctance to come forward is understandable. The reluctance appears to increase exponentially when the group in question are in their late 30's to late 50's, have families, commitments and probably at (the very least) some sort of semirespectability in the eyes of their friends and colleagues. This is known as "the recanting effect" (see, for example, Erowid 2005).

A further point worthy of note is that all of the parties who responded to the participation messages were male. Traditionally (in non-gender specific projects), recruiting female participants for drug research projects has proved problematic. The original heroin project was no different in this respect and by the end of the data collection period 32 of the viable 126 cases were female. This represents $25 \%$ of the final sample included in analysis.

There have been a number of reasons proposed for the gender disparity in drug research, one of which is that women are less likely to participate because they see themselves as having "more to lose" than men and face much greater levels of stigma and social ostracisation. Such stigmatising attitudes are found among health professionals (Samuelsson \& Wallander, 2014) and they appear to apply particularly if the women are parents (see, for example Simpson \& McNulty, 2008).

Of course, one cannot say with any certainty why none of the female participants chose to make contact; the reason could be as prosaic as none of them had heard 
about or seen the invitations - these were, as already noted, made both discreetly and cryptically. Or possibly, if they had heard about or seen these, they were too busy with other domains of their lives to commit themselves. Or perhaps it could be assumed that, as nearly fifteen years had passed since the original project, the lives of the women participants had arguably changed even more than their male counterparts in the form of principal care provider to children, for example. If this is the case, then it underscores the "more to lose" point made above.

As noted, none of the correspondents had any apparent concerns around what the actual effects of long-term drug use might be having on their longer-term health (comparison with an age and gender matched "normal" sample of - supposed - nondrug users and a "stable" methadone sample would have yielded some data on this): all of the concerns were around being "outed", not only as a drug user but as a heroin user, and the subsequent personal and social problems this could potentially cause.

And yet, none of them were particularly averse to the idea of disclosing further detail regarding their heroin use - or non-use - to a suitably vetted, qualified and experienced researcher, either in the form of questionnaires and standardised measures or the taking of notes; as long as their right to total anonymity and confidentiality was understood and upheld.

The problem with this, of course, is that what is yielded from work of this kind is subjective, "soft" data, and this is something that few funders seem prepared to countenance, as it is regarded as of less consequence than data of the more objective and verifiable (and, depending on what is being researched, almost impossible to collect) sort. And so we are back where we started. 


\section{Conclusion}

While it is completely understandable that "hard" data is increasingly regarded as something of a gold standard, there are clear drawbacks to this when it comes to specific "hidden" populations (particularly regarding participation in activities perceived to be of an "aberrant" nature involving drugs and/or sex) the behaviours of whom are likely to result in censure, moral outrage and stigmatization; and these have implications and consequences.

First and foremost, very few funding bodies seem prepared to award grants to researchers working with "soft" data. The above raises questions regarding the fairly narrow scope of this research remit.

Potentially, there is an element here of absence of proof possibly being taken as "proof of absence" as regards what I have termed the "grey middle group" that sits between the black and white of problem users and abstainers. In reality, they exist, but in actuality, there is very little/no hard evidence that "proves" their existence as they are - to an extent, quite understandably given their circumstances - completely opposed to providing the personal details necessary for the gathering of "hard" and "objective" data.

In the light of the above, it may also be necessary to re-evaluate the accuracy and relevance of national crime and health surveys.

In recent years it has been noted that there is an increasing population of older/aging illicit drug users (e.g. Drugscope, 2014). This will presumably be an ongoing situation and while almost certainly it will primarily concern older problem users, there may also be a case to be made for provision for life-long recreational users, as the 
accumulated effects of decades of non-problematic use (be that occasional or something more than occasional) become apparent. Given the concerns of users and for all we know, ex-users - around disclosure of their recreational drug use, this may prove a tough nut to crack.

The aborted project was intended to be the first phase of a larger study, the overall aim of which was to investigate "resilience" to the problems associated with heroin use. Ironically, this "resilience" may at least in part be due to the steadfast refusal of non-problematic users to compromise their anonymity.

For a number of years, the author has taken the view that, rather than focussing solely upon clinical and/or criminal samples in order to determine, so to speak, "why are they as they are", researchers could also focus on the hidden/unobtrusive "grey middle" group in order to determine why they are not like the clinical/criminal groups: what makes them different?

This, of course, is clearly easier said than done and, at least in terms of accumulating hard data, presents significant challenges, particularly around the issues of personal identifiers and signed consent forms. We need to consider whether, in the absence of hard data, is soft data better than no data at all? 


\section{References}

Boekel, L., Brouwers, E., Weeghel, J. \& Garretsen, H. (2015) Comparing stigmatising attitudes towards people with substance use disorders between the general public, GPs, mental health and addiction specialists and clients. International Journal of Social Psychiatry, 61(6): 539-549.

Brown, SA (2015) Stigma towards Marijuana Users and Heroin Users. Journal of Psychoactive Drugs, 47(3), 213-220.

Drugscope (2014) It's about time: Tackling substance misuse in older people. Retrieved 24th July 2015 from:

http://www.drugscope.org.uk/POLICY+TOPICS/OlderPeople Erofeeva, P (2016) The stigmatization of alcohol and drug dependence: its scope and consequences. Journal of Social Policy Studies, 14(3): 377-392.

Erowid (2005) retrieved 24th July 2015 from

https://www.erowid.org/psychoactives/statistics/statistics article2.shtml

Finnigan, F (1996) How non-heroin users perceive heroin users and how heroin users perceive themselves. Addiction Research, 4(1): 25-32.

McElrath K \& McEvoy K (2001) Heroin as Evil: ecstasy users' perceptions about heroin. Drugs: Education, Prevention and Policy, 8(2) 177-189.

McSweeney, T \& Turnbull, P.J. (2007) Exploring user perceptions of occasional and controlled heroin use: a follow-up study. Joseph Rowntree Foundation, York 
Palamar, JJ (2012) A pilot study examining perceived rejection and secrecy in relation to illicit drug use and associated stigma. Drug and Alcohol Review 31(4):573-79

Palamar, JJ (2013) An Examination of Beliefs and Opinion about Drug Use in Relation to Personal Stigmatization towards Drug Users. Journal of Psychoactive Drugs, 45(5), 367-373.

Palamar, JJ, Halkitis, PN \& Kiang, MV (2013) Perceived public stigma and stigmatization in explaining lifetime illicit drug use among emerging adults. Addiction Research and Theory, 21(6), 516-525.

Samuelsson E \& Wallander L (2014) Disentangling practitioners' perceptions of substance use severity: A factorial survey. Addiction Research and Theory, 22(4), 348-360.

Scheibe, L (2017) Visualising "junkies" and "meth heads" - a visual analysis of the persistent negative reputation of heroin and meth users. Drugs and Alcohol Today, 17(1): 40-49.

Shewan, D. \& Dalgarno, P. (2005) Low levels of negative health and social outcomes among non-treatment heroin users in Glasgow (Scotland): Evidence for controlled heroin use. British Journal of Health Psychology, 10, 33-48.

Shewan, D., Dalgarno, P., Marshall, A., Lowe, E. et al (1998) Patterns of heroin use among a non-treatment sample in Glasgow (Scotland). Addiction Research, 6(3), $215-234$ 
Simpson, M. \& McNulty, J. (2008) Different needs: Women's drug use and treatment in the UK. International Journal of Drug Policy, 19(2), 169-175.

Warburton, H., Turnbull, P.J. \& Hough, M. (2005) Occasional and controlled heroin use: not a problem? Joseph Rowntree Foundation, York. 